\title{
Postdigital Afterlife?
}

\section{Maggi Savin-Baden ${ }^{1}$}

Published online: 5 July 2019

(C) Springer Nature Switzerland AG 2019

For most of us, our assumption is that when we die, that is it. There is a possibility of an afterlife, depending on the kind of beliefs you have, but few of us have probably considered creating a virtual human to succeed us when we die. Three or four years ago, digital afterlife inviable just met the memorialisation of digital artefacts. Today, it is not just concerned with the continuation of an active or passive digital presence after death (Savin-Baden et al. 2017) but also with the collation digital assets, the management of post-mortem property and privacy and the creation of a digital immortal to live on after we die. Digital afterlife captures the idea of a virtual space, where information, assets, legacies and remains reside as part of the cyber soul and assumes a digital presence that may or may not continue to exist, whereas 'immortality' implies a presence, in some form at least, ad infinitum (Savin-Baden and Mason-Robbie forthcoming). Whilst these terms may be used interchangeably, afterlife is a broader and more flexible construct as it does not contain assumptions about the duration or persistence of the digital presence.

Some postdigital authors suggest/imply that digital immortality, because of its digital-ness, is not separable from biological/human existence (for example Jandrić et al. 2018). However, I would argue that digital afterlife may have some continuous/ contiguous components that are postdigital but digital immortals do not. This is because to date, digital immortals are passive, do not have sentience and are unlikely to achieve it in at least the next 40 years. There is no ineffable plan here, but there is a question of agency.

It is not clear what or whom is created or how agency might be located in all these new debates. Agency according to Giddens is the 'capacity to make a difference' (Giddens 1984: 14), and technology, from Giddens' perspective, cannot be an agent. I would still suggest virtual humans or digital immortals could be said to have some kind of agency. As Turkle suggests (Turkle 2005, 2011) computers are not merely objects that make our lives more efficient but are subjects that are intimately and ultimately linked to our social and emotional lives. Turkle argues that computers change not only what we do but also how we think about the world and ourselves. What is particularly

Maggi Savin-Baden

m.savinbaden@worc.ac.uk

1 University of Worcester, Worcester, UK 
important here is the structure-agency debate that introduces questions about the nature of social behaviour: whether it is ultimately predictable in terms of the creative volition of the individual or is largely a product of socialization, interaction and greater social structures.

There has been relatively little consideration of agency in relation to digital afterlife. Much of the work in this area in relation to virtual humans has concentrated on attributed agency. Attributed agency is both the sense of agency and the way in which agency is attributed to humans, virtual humans or digital immortals. In the case of virtual humans, it seems to be evident that the context affects the sense of agency. For example, Obhi and Hall (2011) found that humans consider face-to-face shared action with other humans different from human-computer shared actions. The findings indicate that attributed agency tends to be over-ruled when the participant is aware the computer is a co-actor. Studies such as this seem to imply that humans are more likely to attribute agency to other humans but not to virtual humans.

Post-humanism seeks to break down binary distinctions between 'human', 'machine' and 'text' and between 'nature' and 'culture'; it also rejects dualisms that are used to define being such as subject/object (Hayles 1999, 2012). Thus, post-humanist theory is used to question the foundational role of 'humanity'. It prompts consideration of what it means to be a human subject and the extent to which the idea of the human subject is still useful. This has overlap with actor network theory where the arguments centre on the idea that actors may be both human and non-human; thus, for example, supermarket products and digital devices are seen as actors that have influence, but it is not clear how all this relates to the creation of a digital afterlife.

Yet, digital media are currently being used to expand the possibilities of commemorating the dead and managing the grief of those left behind and complementing and sometimes replacing the well-established formal structures and rituals of Christianity and other faiths. Despite increasing research into death online (Hutchings 2017), there is little exploration of the impact of the creation of digital immortals on religious practices and grief management. For instance, Walter (2017) suggests there are increasing shifts in perceptions of embodiment, death and afterlife. The growth of personality capture, mind uploading and computationally inspired life after death have huge implications for the future of religion, understandings of the afterlife and the influence of the dead surviving in society. Wagner notes: '[b]oth religion and virtual reality can be viewed as manifestations of the desire for transcendence, the wish for some mode of imagination or being, that lies just beyond the reach of our ordinary lives' (Wagner 2012: 4). Yet, few Christian and other faith leaders have examined the potential for the positive impact of digital media and digital immortality creation in religious contexts.

This sense of investment in flesh (through the incarnation) results in a perception that what happens in the digital context is disembodied and therefore less real, less incarnational and less faith-related (O' Donnell 2019). Gooder's (2016) work on the body sees resurrection as a continuation of this life, prioritizing a resurrection of the material body, and is therefore committed to the flesh of this life carrying over in the resurrected life. One of the central difficulties is that Christianity and other faiths find digital afterlife creation disconcertingly disembodied, and it is not clear whether it promotes particular views about bodily forms in the afterlife. Furthermore, digital afterlife creation may prevent us from being free to die (Davies 2008: 106), as well as introducing questions about how 'the dead' might be classified. 
Marking the end of life today increasingly includes memorials, whether sites of roadside crashes, family and friends 'saying a few words' or listening to the deceased's favourite music during services. It is evident that there have been recent moves away from traditional funeral services focusing on the transition of the deceased into the future world beyond towards the rise in popularity of memorial content within funerals and commemorative events which focus on holding on to the memories of the deceased by those left behind Irrespective of religious belief, most present at memorials can reflect on a person's life and find something worth recalling. It is a shared act that induces a sense of singleness of purpose without introducing divisive beliefs. In a postmodern context of mixed religious beliefs and secular outlooks, this affords a safe ritual space (Brock 2010: 64). Now digital afterlife represents the next quantum leap: creating potentially everlasting memorials.

Digital afterlife has moved beyond digital memorialisation towards a desire to preserve oneself after death. Preserving oneself or being preserved by someone else may affect both the dying person's peace of mind and the well-being of the bereaved. Further, it is not clear whether the possibility of digital immortality or the use of digital media alters thoughts about the mind-body connection, and whether interaction with a digital immortal alters one's spiritual journey through grief. Afterlife and resurrection remain troublesome because they are couched in mystery. Philosophical and theological discourse cannot explain resurrection of the body, because the human body itself is not reducible to simple description or ready comprehension. Chauvet (1995), for example, sees the human as a subject whose corporality is a 'triple body' comprised of culture, tradition and nature.

New practices suggest that the possibilities of 'living on' through such technological innovations have the potential to change the religious landscape radically, and recent developments suggest that there will be a socio-political and psychological impact that will affect understandings about embodiment, death and the social life of the dead and create new forms of post-mortem veneration. Thus, digital afterlife may have the kind of symmetry that Jones (2018) suggests between digital remains and digital afterlife creation which may or may not involve a digital immortal. Digital afterlife is not ultimately about digitizing biology but is akin to Peters' (2012) notion of bio-informational capitalism since the focus is on collating and creating post-mortal artefacts in ways that reflect knowledge capitalisms and is: 'based on a self-organizing and self-replicating code that harnesses both the results of the information and new biology revolutions and brings them together in a powerful alliance that enhances and strengthens or reinforces each other' (Peters 2012: 105).

Thus, digital afterlife creation is postdigital, but passive digital immortality is not since artefacts are merely stored behind an avatar. Whole brain emulation whereby brain scan data is translated into a software based on the neurons and other key parts of the brain and the singularity whereby the view that there will be a time in the future technological growth becomes uncontrollable and irreversible do suggest that 20502100 might be the time period in which the development of really complex virtual humans capable of being called virtual sapiens will occur (Burden and Savin-Baden 2019), but whether active digital immortals will emerge before then is questionable. 


\section{References}

Brock, B. (2010). Christian ethics in a technological age. Grand Rapids: W. B. Eerdmans Publishing Co.. Burden, D., \& Savin-Baden, M. (2019). Virtual humans: Today and tomorrow. New York: Taylor and Francis. Chauvet, L. M. (1995). Symbol and sacrament: A sacramental reinterpretation of Christian existence. Trans. P. Madigan and M. Beaumont. Collegeville, MI: Liturgical Press.

Davies, J. D. (2008). The theology of death. London: Continuum.

Giddens, A. (1984). The constitution of society. Cambridge: Polity Press.

Gooder, P. (2016). Body: Biblical spirituality for the whole person. London: SPCK Publishing.

Hayles, K. (1999). How we became posthuman: Virtual bodies in cybernetics, literature and informatics. Chicago: University of Chicago Press.

Hayles, K. (2012). How we think: Digital media and contemporary technogenesis. Chicago: University of Chicago Press.

Hutchings, T. (2017). "We are a united humanity": Death, emotion and digital media in the church of Sweden. Journal of Broadcasting \& Electronic Media, 61(1), 90-107. https://doi.org/10.1080 /08838151.2016.1273930.

Jandrić, P., Knox, J., Besley, T., Ryberg, T., Suoranta, J., \& Hayes, S. (2018). Postdigital science and education. Educational Philosophy and Theory, 50(10), 893-899. https://doi.org/10.1080 /00131857.2018.1454000.

Jones, C. (2018). Experience and networked learning. In N. Bonderup Dohn, S. Cranmer, J. A. Sime, M. de Laat, \& T. Ryberg (Eds.), Networked learning: Reflections and challenges (pp. 39-56). Springer International.

O’ Donnell, K. (2019). Digital theology: Constructing theology in a digital age. London: Bloomsbury.

Obhi, S. S., \& Hall, P. (2011). Sense of agency in joint action: Influence of human and computer co-actors. Experimental Brain Research, 211(3-4), 663-670. https://doi.org/10.1007/s00221-011-2662-7.

Peters, M. A. (2012). Bio-informational capitalism. Thesis Eleven, 110(1), 98-111. https://doi.org/10.1177 $/ 0725513612444562$.

Savin-Baden, M., Burden, D., \& Taylor, H. (2017). The ethics and impact of digital immortality. Knowledge Cultures, 5(2), 11-19. https://doi.org/10.22381/KC52201711.

Savin-Baden, M., \& Mason-Robbie, V. (forthcoming). Perspectives on Digital Afterlife. In M. Savin-Baden \& V. Mason-Robbie (Eds.), Digital Afterlife. New York: Taylor and Francis.

Turkle, S. (2005). The second self: Computers and the human spirit (2nd ed.). Cambridge, MA: MIT Press. Turkle, S. (2011). Alone together. New York: Basic Books.

Wagner, R. (2012). Godwired: Religion, ritual and virtual reality. New York: Routledge.

Walter, T. (2017). How the dead survive: Ancestors, immortality, memory. In M. H. Jacobsen (Ed.), Postmortal society. Towards as sociology of immortality (pp. 19-49). London: Routledge. 